Тимофеев Е. В. ${ }^{1}$, Мамев Э. Г. ${ }^{2}$, Земцовский Э. В. ${ }^{1}$

1 - ФГБОУ ВО «СПбГПМУ» МЗ РФ, 194100, Санкт-Петербург, ум. Аитовская, А. 2,

2 - ФГБУ «НМИЦ им. В.А. Алмазова» МЗ РФ, 197341, Санкт-Петербург, ум. Аккуратова, А. 2

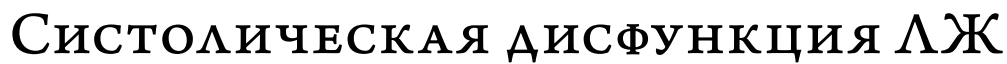

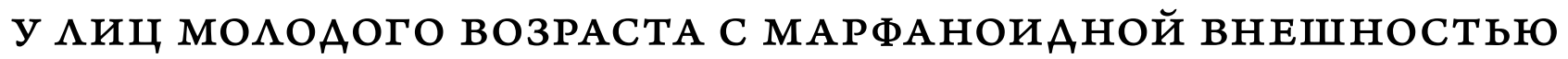

\author{
КАЮЧЕВЫЕ САОВА: МАРФАНОИАНАЯ ВНЕШНОСТЬ, КОСТНЫЕ ПРИЗНАКИ АИЗЭМБРИОГЕНЕЗА, СИСТОАИЧЕСКАЯ АИСФУНКЦИЯ АЖ, \\ АЕФОРМАЦИЯ МИОКАРАА, РАСШИРЕНИЕ АОРТЫ \\ Ссылка для ииттирования: Тимофеев Е. В., Малев Э.Г., Земцовский Э.В.

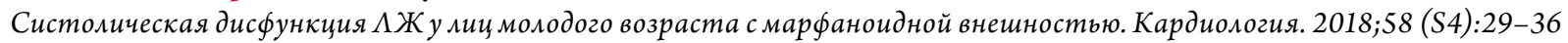 \\ РеЗюме
}

Актуальность. Согласно Российским рекоменАациям по Аиагностике наследственных нарушений соеАинительной ткани (2013), выделяют ряА наследственных синдромов и диспиастических фенотипов, наиболее распространенным из которых явмяется марфаноидная внешность (МВ). МВ Аиагностируется при наличии не менее 4 костных признаков, среди которых наиболее значимыми являются арахнодактилия, Аолихостеномелия, высокое арковидное нёбо, килевиАная и воронкообразная Аеформации грудной клетки. Известно, что у миц с синдромом Марфана Ааже в молодом возрасте выявляются признаки систо-

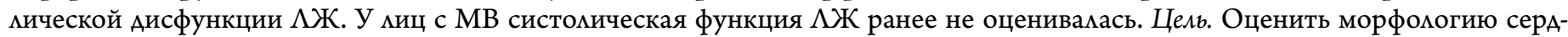
ца и систолическую функцию $\Lambda$ у практически здоровых миц молодого возраста с МВ. Материалы и методы. Обследовано

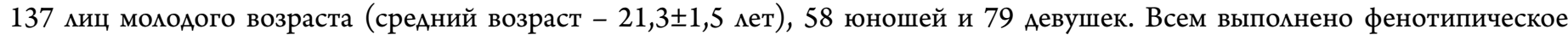
и трансторакальное ЭхоКГ (Vivid 7 Dimension, GE) обследования. У 24 пациентов с МВ и 42 человек без признаков МВ (контроль) оценена радиальная и циркуляная Аеформации $\Lambda$ с использованием тканевого Аатчика и последующей оценкой на рабочей станции EchoРAC»08 (GE). Результаты. У миц с МВ по сравнению с контролем выявлен достоверно больший Аиа-

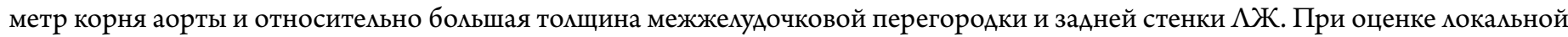
сократимости миокарда $\Lambda Ж$ показано снижение систолической циркумярной деформации большинства сегментов на срединном

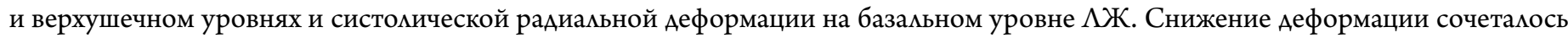
со снижением ее скорости в этих же сегментах. Заключение. Аля миц молоАого возраста с МВ при отсутствии «больших» при-

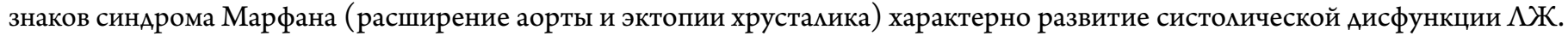

Timofeev E. V. ${ }^{1}$, Malev E. G. ${ }^{2}$, Zemtsovsky E. V. ${ }^{1}$

1 - St. Petersburg State Pediatric Medical University, Litovskaya 2, St. Petersburg 194100

2 - Almazov Federal Medical Research Centre, Akkuratova 2, St. Petersburg 197341

\section{LEFT VENTRICULAR SYSTOLIC DYSFUNCTION IN YOUNG SUBJECTS WITH MARFANOID HABITUS}

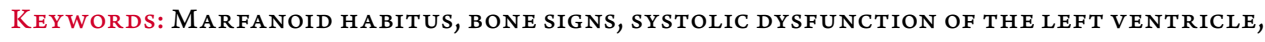
MYOCARDIAL DEFORMATION, AORTIC DILATATION

For citation: Timofeev E. V., Malev E. G., Zemtsovsky E.V.

Left ventricular systolic dysfunction in young subjects with marfanoid habitus. Kardiologiia. 2018;58 (S4):29-36

\section{SUMMARY}

Background. In Marfan syndrome early impairment of left ventricular systolic function has been reported. Our aim was to evaluate the left ventricular systolic function in young adults with Marfanoid habitus $(\mathrm{MH})$ (includes arachnodactylia, dolichostenomelia, high palate, deformations of the thorax). Methods: We studied 137 young subjects (mean age 21.3 \pm 1.5 ) - 58 male, 79 female. Transthoracic echocardiography (Vivid 7 Dimension, GE) was performed in 24 asymptomatic MH with excluded Marfan syndrome and 42 healthy control subjects. Radial and circumferential systolic strain and strain rate were determined using spackle tracking (EchoPAC $\gg 08$, GE). Results: Ascending aorta diameters were larger in subjects with MH. LV mass index did not differ significantly between groups, but interventricular septum and posterior wall thickness were greater in MH group. Local LV radial and circumferential systolic deformation indices were significant decreased in MH group. Conclusions: Young adults with MH in the absence of major findings of Marfan syndrome (ascending aortic aneurysm and ectopia lentis) have decreased LV systolic function.

$\mathrm{B}$ опросы классификации и диагностики наслеАственных нарушений соединительной ткани (ННСТ) до сих пор остаются неАостаточно разработанными. Согласно национальным рекомендациям $[1,2]$, все ННСТ следует разделять на классифицированные и неклассифицирован- ные. К классифицированным ННСТ относят Аостаточно редко встречающиеся заболевания, Аиагностика которых опирается на согласованные международные критерии - Гентские критерии аля синдрома Марфана [3, 4], Вимльфраншские - Аля синдрома Элерса-Аанио $[5,6]$, 
Брайтонские - Аля синдрома гипермобильности суставов, пересмотренные Бейтоном $[7,8]$. Аиагностика этих ННСТ разработана с учетом генетических Аанных. Так, в качестве генетической основы синдрома Марфана и родственных ему ННСТ, характеризующихся признаками вовмечения костной системы, называют мутации гена фибримлина-1 (FBN-1) [9]. С дефектами FBN-1 ассоциированы и сами костные признаки синдрома Марфана. Среди неклассифицированных ННСТ (в России чаще называемых дисплазиями соединительной ткани) комитет экспертов РКО предлагает выделять наследственные синдромы, в первую очередь - синдром пролапса митрального кмапана (ПМК), и ряА Аиспластических фенотипов - марфаноидную внешность (МB), марфаноподобный фенотип, эмерсоподобный фенотип, Аоброкачественную гипермобильность суставов. Наиболее распространенным и относительно изученным явмяется фенотип МВ [10].

Аиагностика МВ основана на выявлении тех же костных признаков, что и при синдроме Марфана - килевиАной и воронкообразной деформации груАной кметки, сколиотической деформации позвоночника, высокого арковидного нёба и Аругих мицевых Аизморфий, плоскостопия, арахнодактилии, Аолихостеномелии [11]. А^я Аиагностики МВ используется амгоритм, изможенный в Российских рекоменаациях $[1,2]$, согласно которому достаточно выявления мюбых 4 костных признаков, среди которых обязательно сочетание арахнодактилии и Аолихостеномелии. Ранее сообщалось о частом выявмении у миц с МВ, оцененной согласно рекоменАациям PКО, вегетативной Аисфункции [12]. ОАнако рекоменАованный подхоА к выявмению $\mathrm{MB}[1,2]$ не учитывает ни специфичность отдельных признаков, ни гендерные различия. МежАу тем бымо показано, что большинство костных признаков существенно чаще выявмяются у миц мужского пола, что требует коррекции алгоритма Аиагностики с учетом пола обследуемого. Кроме того, неоАинаковой оказалась и специфичность отдельных признаков - установлено, что с дефектами соединительной ткани тесно связаны, кроме арахнодактилии и долихостеномелии, такие признаки, как Аеформация грудной кметки и арковиАное нёбо. Это позволимо нам скорректировать подходы к выявлению МВ - этот Аиспластический фенотип мы преАлагаем диагностировать при выявлении 4 костных признаков, среди которых обязательно сочетание арахнодактилии и долихостеномелии и, кроме того, при наличии не менее 2 Аля мужчин и не менее 1 Аля женщин высокоспецифичного признака - деформации груАной кметки или арковиАного нёба. При таком подходе МВ как Аиспластический фенотип выявмяется у $16 \%$ юношей и 9\% девушек [13]. Морфологические особенности серАца и состояние мокальной сократительной функции $\Lambda Ж$ у миц с МВ ранее не оценивались.
В то же время морфофункциональные характеристики серАца при Аругих ННСТ, относящихся к группе фибримлинопатий, изучены достаточно хорошо. Так, многими исследователями признаются значимые изменения структуры сердца у миц с синдромом Марфана и первичным ПМК, приводящие к снижению систолической функции $\Lambda Ж$ у таких пациентов [14-19]. Указывается также, что опредемение ФВ не явмяется надежным маркером кардиомиопатии при этих ННСТ, так как Алительное время этот показатель остается сохранным $[14,19]$. Более информативным оказалось использование оценки деформации миокарда с помощью методики speckle tracking (покадровое отслеживание Авижения неоднородных «крапинок» в толще миокарАа). Это Аает преАставление о региональной сократительной функции миокарда $\Lambda$. Аеформация миокарда в систолу, обусловленная сокращением саркомеров, привоАит к уменьшению объема помости $\Lambda$ и состоит из 3 составмяющих: продольного укорочения, циркулярного укорочения и радиального утолщения в систолу и выражается в процентах от исходного размера анализируемого участка миокарда [20]. Скорость деформации (strain rate) явмяется производным от деформации показателем и определяется как время, в течение которого происходит деформация миокарда и выражается в $\mathrm{c}^{-1}$. Известно, что уже в молодом возрасте Аля пациентов с синдромом Марфана характерно развитие кардиомиопатии, проявмяющейся снижением скорости и величины продольной систолической деформации нижней, передней и боковой стенок $\Lambda$ на всех уровнях - базальном, срединном и верхушечном и уменьшение систолической радиальной деформации (РА) и ее скорости во всех оцениваемых сегментах [21]. Следует отметить также, что, несмотря на то, что ФВ у пациентов с синдромом Марфана оказалась существенно ниже по сравнению с контрольной группой, она все же не выходияа за предемы нормы [21]. Выявменные изменения систолической Аеформации $\Lambda$ Жочетаются с относительно большей толщиной миокарАа межжелудочковой перегородки (МЖП) при сравнительно одинаковой толщине задней стенки (3С) $\Lambda Ж$. Аналогичные изменения систолической деформации $\Lambda Ж$ описываются и у бессимптомных (без клинических признаков $\mathrm{CH}$ и тяжелой митральной регургитации) пациентов с первичным ПМК [18].

\section{Материалы и методы}

В рамках исследования было обследовано 137 миц

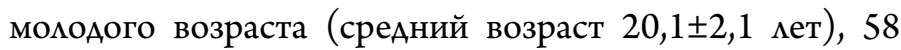
юношей и 79 девушек. Амя оценки возрастной Аинамики морфофункциональных изменений серАца в исслеАование включены 111 пациентов старших возрастных групп (средний возраст 66,8 99,6 мет) и 9 мужчин с верифицированным синдромом Марфана (средний возраст $27,9 \pm 9,3$ мет). 
ОРИГИНААЬНЫЕ СТАТЬИ

Аиагностику МВ осуществляли согласно Российским рекомендациям с учетом уточненных критериев. К МВ относили миц, имеющих не менее 4 костных признаков, среАи которых было обязательным сочетание арахнодактилии (выявмение по крайней мере 1 симптома - большого пальца или запястья) и долихостеномелии (выполнение хотя бы 1 коэффициента - отношение размаха рук к росту $>1,03$ и соотношение верхнего и нижнего сегментов тела $<0,89$ ), а кроме того, наличие хотя бы еще 1 Аля миц женского пола и не менее 2 Аля миц мужского пола высокоспецифичного признака - Аеформации груАной клетки (килевидной или воронкообразной) или высокого арковидного нёба. У миц старших возрастных групп МВ выявмяли с учетом изменения информативности ряда признаков с возрастом - к наиболее надежным костным признакам относими деформации грудной кметки, симптомы арахнодактимии и высокое арковидное нёбо. В то же время известно, что специфичность таких признаков, как сколиотическая Аеформация позвоночника и плоскостопие у миц старшего возраста крайне низки, а снижение высоты межпозвоночных дисков и связанное с этим уменьшение роста может приводить к неверному расчету коэффициентов Аолихостеномелии [22].

Всем обследованным выполнена ЭхоКГ в 2D, Аопплеровском и цветном М-режиме по стандартному протоколу (Vivid 7 Dimension, General Electric, матричный фазированный Аатчик 3,5 МГц). Аля искмючения возможных генАерных вмияний оценка морфометрических характеристик серАца проводилась только у лиц мужского пола. Группу МВ составили 26 юношей, в группу контроля вошли 32 юноши. Анализировались Аиаметры начального и восходящего отдеков аорты, толщина миокарда $\Lambda$, масса миокарда $\Lambda$

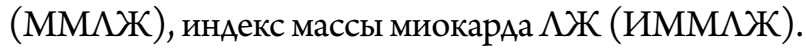

Расширение корня аорты оценивалось по значению $\mathrm{Z}$-критерия $\geq 2$ Аля пациентов в возрасте старше 20 мет и $\mathrm{Z} \geq 3$ Аля пациентов моложе 20 мет. Расчет $\mathrm{Z}$-критерия: $\mathrm{Z}=($ АКа $-А А К а) / \mathrm{k}$, гАе $\mathrm{k}$ Амя возраста до 20 мет - 0,18; от 20 Ао 39 мет - 0,24; старше 40 мет - 0,37; АКа - Аиаметр корня аорты на уровне синусов Вальсальвы (см); ААКа - Аолжный диаметр корня аорты (см). Расчет Аолжного диаметра аорты дмя данного возраста (Roman M.J.,

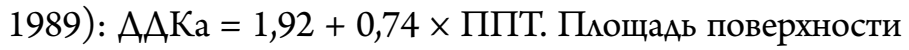
тела (ППТ) рассчитывалась по формуле Аюбуа (DuBois and DuBois, 1916) [2]. ММАЖ опредемялась по формуле Devereux R. B. et al. (1986).

Систолическая PA и циркулярная Аеформация (ЦА) оценивались в парастернальных коротких сечениях на 3 уровнях с помощью методики speckle tracking, при частоте каАров серошкального изображения 50-55/c. В кажАом сечении записывалось по 1 кардиальному цикму с последующим анализом на рабочей станции EchoPAC’08 (GE Healthcare). Определение Аеформации и скорости

\section{Пресс-релиз}

\section{Переход на новую форму}

Уважаемые коллеги!

Компания АО «Сервье» сообщает о завершении с января 2018 г. производства формы лекарственного препарата Предуктал МВ 35 мг и полном переходе на новую форму выпус ка - Предуктал ОД 80 мг.

Новая лекарственная форма - Предуктал ОД (МНН триметазидин) - капсулы с пролонгированным высвобождением, дозировка 80 мг, упаковка №30 и №60.

Режим дозирования новой формы Предуктал ОД 80 мг - одна капсула в сутки. Благодаря инновационной технологии при приеме препарата обеспечивается пролонгированное высвобождение триметазидина в ЖКТ с поддержанием его стабильной концентрации в плазме крови в течение 24 часов. Применение новой формы препарата позволит значительно увеличить приверженность пациентов лечению за счет однократного приема, что в свою очередь позволит более эффективно контролировать симптомы стабильной стенокардии.

Фармакокинетическая эквивалентность Предуктала МВ для двукратного приема $(35$ мг) и новой формы Предуктала ОД 80 мг для однократного приема доказана в сравнительном исследовании, необходимом для регистрации препарата и проведенном согласно европейским требованиям и стандартам.

Предуктал ОД 80 мг сохраняет все свойства Предуктала МВ 35 мг, обеспечивая: высокую эффективность по снижению приступов стенокардии;

улучшение функционального класса ИБС и ХСН;

уменьшение ремоделирования миокарда и повышение выживаемости больных.

Компания AO «Сервье» направляет максимум своих усилий на удовлетворение потребностей пациентов благодаря вкладу в терапевтический прогресс. Именно это послужило стимулом для создания инновационной, более удобной и эффективной формы выпуска. Использование Предуктала ОД 80 мг позволит повысить приверженность большинства пациентов проводимой терапии на фоне высокой эффективности и переносимости.

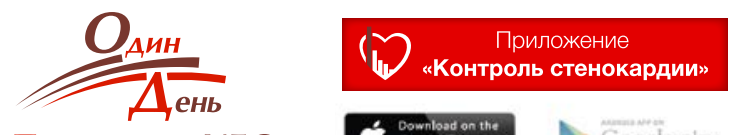

Пациента с ИБС

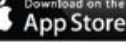

Apple, the Apple logo and Iphone are trademarks of Apple Inc., registred in the U.S. and other countries.
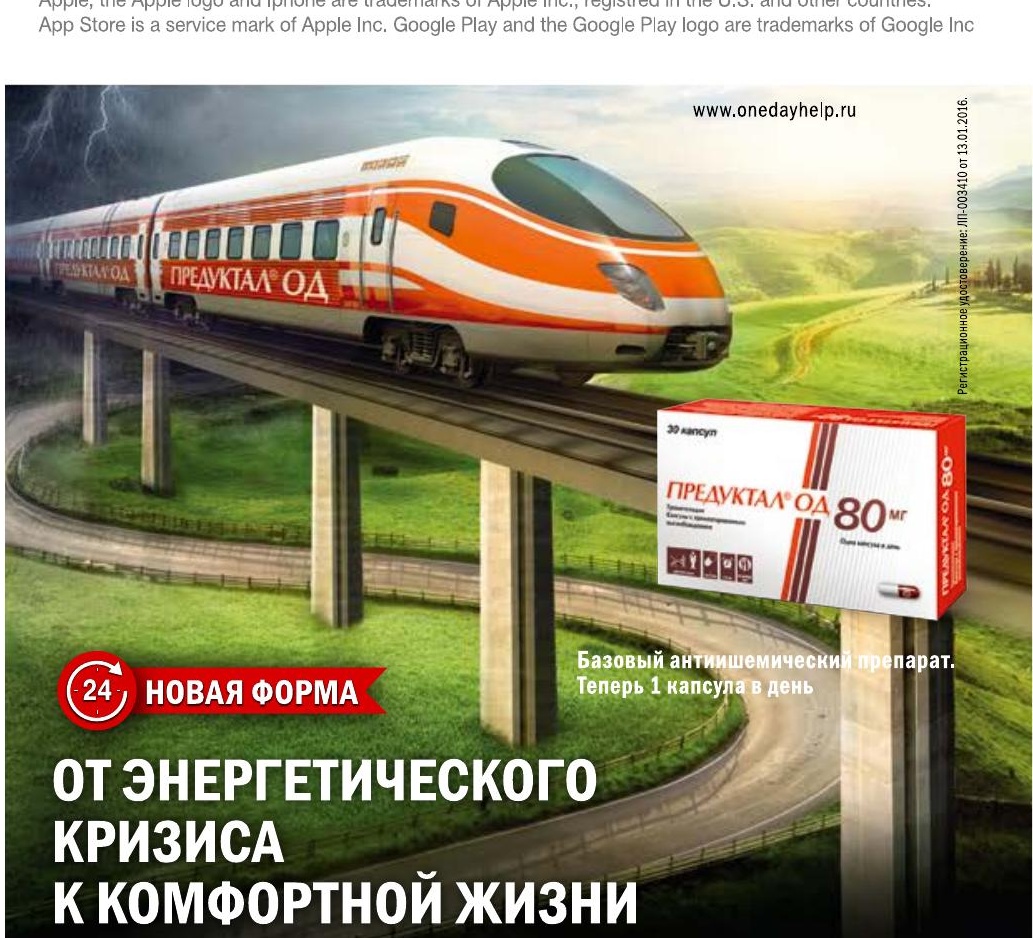
К ПРИМЕНЕНИЮ.* Алительная терапия ишемической болезни сердща: профилактика Приступов

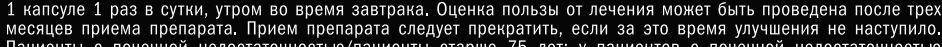

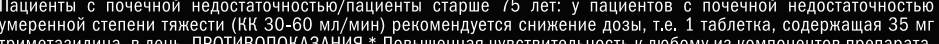
болезнь Паркинсона, симптомы паркинсонизма, тремор, синдром “беспокойных ног” и другие, связанные с ними двигательные нарушения. Тяжелая почечная недостаточность (КК < 30 мл/ Мин). Непереносимость фруктозы/сахаро-

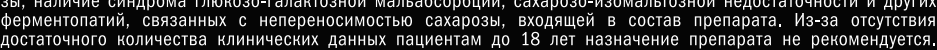

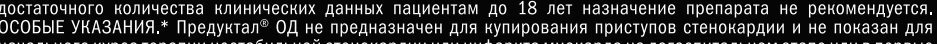

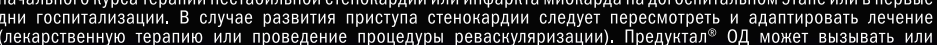
ухудшать симптомы паркинсонизма (тремор, акинезию, повышение тонуса), поэтому следует проводить регулярное
набльдение пациентов, особенно пожилого возраста. Могут отмечаться случаи падения, связанные с неустойчиво-

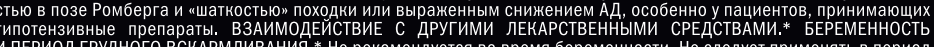

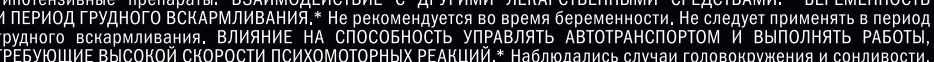
ТРЕБУЮЩИЕ ВЫСОКОЙ СКОРОСТИ ПСИХОМОТОРНЫХ РЕАКЦИЙ.* Наблюдались случаи головокружения и сонливости,

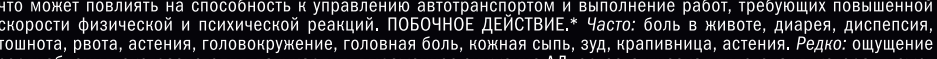

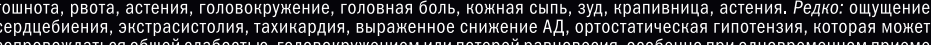

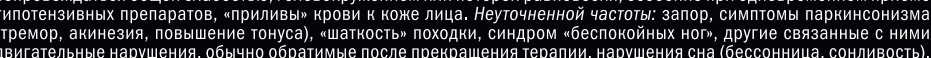
двигательные нарушения, обычно обратимые после прекращения терапии, нарушения сна (бессонница, сонливость), точной концентрации аденозинтрифосфата (АТФ) путем сохранения энергетического метаболизма клетон

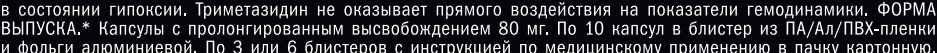
и фольги алюминиевой. По 3 или 6 блистеров с инструкцией по медицинскому применению в пачку картонную.
По 9 капсул в блистер из ПА/Ал/ПХ--пленки и фольги алюминиевой. По 36 блистера с инструкцией по медицинскому По 9 капсул в влистер из ПА/Ал
примененению в пачку картоннуг 
Табмица 1. Аиаметр груАной аорты у миц мужского пола с марфаноидной внешностью

\begin{tabular}{|c|c|c|c|}
\hline Показатемь & $M B(n=26)$ & Контроль $(\mathrm{n}=32)$ & $p(t-т е с т)$ \\
\hline Ao, мм & $30,42 \pm 4,76$ & $28,03 \pm 3,63$ & 0,03 \\
\hline Ао/ППТ, мм/м² & $17,52 \pm 2,80$ & $15,89 \pm 2,51$ & $0,02(d=0,61)$ \\
\hline вАо, мм & $26,63 \pm 4,89$ & $24,58 \pm 3,19$ & 0,05 \\
\hline вАо/ППТ, мм/м² & $15,15 \pm 2,38$ & $13,80 \pm 2,31$ & $0,03(\mathrm{~d}=0,58)$ \\
\hline
\end{tabular}

Ао - диаметр начального отдела аорты, ППТ - площадь поверхности тела, вАо - диаметр восходлщего отдела аорты

Аеформации проводилось согласно международным рекомендациям [23]. Амя оценки систолической деформации была сформирована группа МВ (24 пациента, из них 66,7\% мужчин), контрольную группу составили 42 практически зАоровых человека с единичными костными признаками (мужчин 57,1\%). Группы достоверно не размичались по возрасту и поку.

Статистика: Аанные преАставлены как среднее \pm стандартное отклонение. Значимость размичий межАу количественными признаками, имеющими нормальное распределение (ММАЖ, ИММАЖ, Z-критерий, ЦА и РА) определялась при помощи t-критерия Стьюдента $(\mathrm{p}<0,05)$. Статистическая обработка Аанных была выполнена при помощи программы Statistica 8 (StatSoft, Inc.).

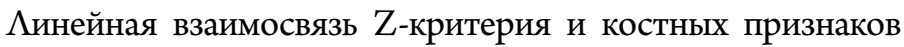
оценивалась с помощью коэффициента ранговой корреляции Спирмена $(\mathrm{p}<0,05)$.

\section{Результаты}

ОАним из наиболее специфичных кардиальных проявлений синдрома Марфана, зачастую обусловливающим исход этого заболевания, явмяется аневризма грудного отАека аорты. МежАу тем в рекомендациях РКО отмечается, что у пациентов старших возрастных групп нередко выявмяется пограничное расширение аорты, что может рассматриваться как малая аномалия сердца и свидетельствовать о слабости соединительнотканного каркаса сердца и магистральных сосудов $[2,4]$. У миц молодого возраста морфометрические характеристики аорты в зависимости от наличия признаков $\mathrm{MB}$ ранее не оценивали.

Мы сравнили диаметр начального и восходящего отдемов аорты у юношей с признаками $\mathrm{MB}$, оцененной согласно уточненному амгоритму, и молодых мужчин с единичными костными признаками (табк. 1).
У юношей с $\mathrm{MB}$ по сравнению с группой контроля выявлен сравнительно больший Аиаметр начального и восходящего отделов аорты. Эти различия становятся более очевидными при отнесении их к ППТ. ОАнако ни у 1 обслеАованного нами пациента молодого возраста не было выявмено расширения аорты - Z-критерий не превышал пороговые значения. МежАу тем известно, что значимое расширение грудной аорты даже у миц с синдромом Марфана часто удается обнаружить только в более старшем возрасте. Аля проверки взаимосвязи костных признаков и морфометрических характеристик аорты был проведен корремяционный анализ межАу костными признаками и значениями Z-критерия в группе пациентов старших возрастных групп. Нами выявлены достоверные положительные корреляционные связи межАу значением Z-критерия >2,0 и наличием таких высокоспецифичных костных признаков, как арковидное нёбо $(\mathrm{r}=0,31)$, арахнодактилия $(\mathrm{r}=0,45)$ и деформация грудной кметки $(\mathrm{r}=0,43), \mathrm{p}<0,05$. Напомним, что эти признаки явмяются обязательными Амя выявления $\mathrm{MB}$ согласно уточненному алгоритму.

Аалее была оценена встречаемость расширения аорты у пациентов старших возрастных групп с MB (25 человек). В анализ были включены также результаты обследования 9 пациентов с верифицированным диагнозом синдрома Марфана («эталонная» группа). В контрольную группу вошли 86 пациентов того же возраста с единичными (не более Авух) костными признаками (рис. 1). Расширение аорты, оцененное при превышении порогового значения Z-критерия $>2,0$, выявмяется у кажАого 4-го обследованного как группы МВ, так и среди больных синдромом Марфана. ОАнако следует подчеркнуть, что абсолютные размеры диаметра аорты у больных синаромом Марфана были существенно выше $(43,4 \pm 15,3$ мм), нежели в группе MB (36,3 $\pm 5,1$ мм),

Таблица 2. Показатели морфометрии сердца у юношей с марфаноидной внешностью

\begin{tabular}{l|ccc} 
Показатемь & MB $(\mathbf{n = 2 6 )}$ & Контромь $(\mathbf{n}=\mathbf{3 2})$ & $\mathbf{p}(\mathbf{t}$-тест) \\
\hline МЖП, мм & $8,82 \pm 1,15$ & $8,21 \pm 1,10$ & $0,04(\mathrm{~d}=0,54)$ \\
\hline 3С, мМ & $8,33 \pm 0,82$ & $7,73 \pm 1,09$ & $0,02(\mathrm{~d}=0,92)$ \\
\hline ММ, г & $157,58 \pm 52,37$ & $134,95 \pm 45,16$ & 0,08 \\
\hline ИММ, г $/ \mathrm{M}^{2}$ & $85,9 \pm 24,7$ & $75,2 \pm 21,8$ & 0,08 \\
\hline
\end{tabular}

МЖП - толщина межжелудочковой перегородки, ЗС - толщина задней стенки, ММ - масса миокарда, ИММ - индекс массы миокарда 


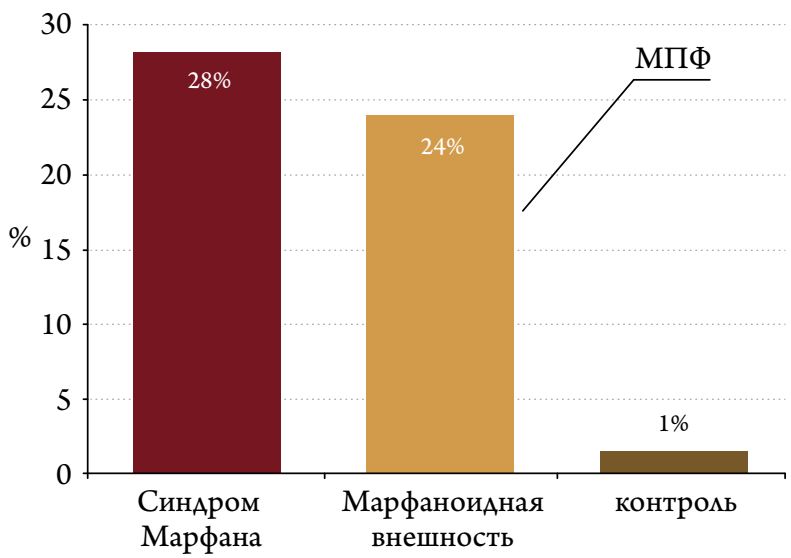

Рисунок 1. Частота выявления расширения корня аорты (Z-критерий $>2,0)$ у пациентов старших возрастных групп с синдромом Марфана и марфаноидной внешностью
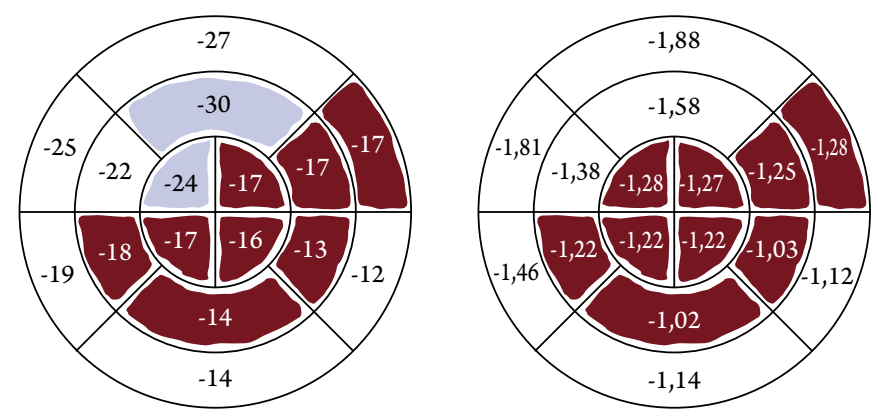

Темный цвет - статистически достоверное снижение величины и скорости Аеформации, светлый цвет - статистически достоверное повышение величины и скорости деформации, белый цвет - без существенных различий

Рисунок 2. Значения пиковой систолической циркулярной Аеформации (слева) и ее скорости (справа) у миц молодого возраста с марфаноиАной внешностью
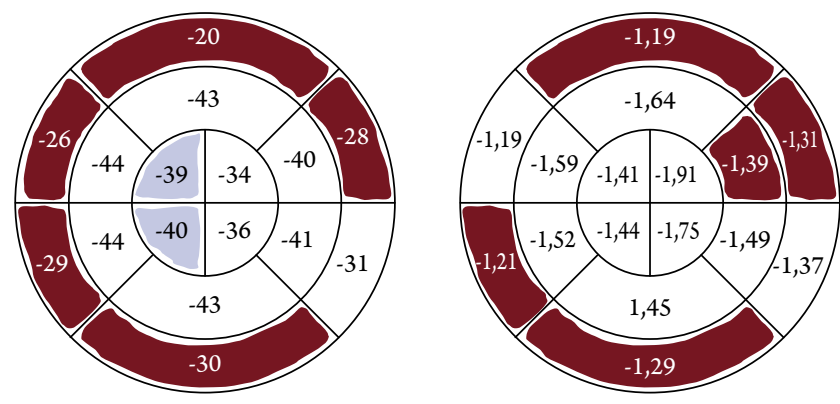

Темный цвет - статистически достоверное снижение величины и скорости Аеформации, светлый цвет - статистически достоверное повышение величины и скорости Аеформации, белый цвет - без существенных различий

Рисунок 3. Значения пиковой систолической радиальной Аеформации (слева) и ее скорости (справа) у миц молодого возраста с марфаноидной внешностью

$\mathrm{p}=0,04$. Таким образом, в группе миц старшего возраста с МВ можно говорить кишь о пограничном расширении корня аорты. Напомним, что, согласно рекомендациям
РКО, сочетание признаков МВ и пограничного расширения аорты позволяет диагностировать марфаноподобный фенотип. Выявценная связь межАу признаками $\mathrm{MB}$ и диаметром аорты подтвержАается и тем фактом, что в группе с единичными костными признаками расширение аорты практически не выявмямось (1\%).

Аалее были оценены морфологические характеристики

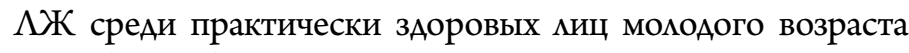
с МB (табл. 2).

У юношей с $\mathrm{MB}$ по сравнению с контрольной группой

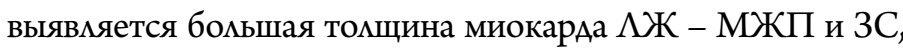
что обусловливает недостоверно более высокие значения ИММАЖ. Следует отметить, что толщина миокарАа ни у 1 обследованного не превышала нормальные значения, что не позволяет говорить о гипертрофии миокарАа $\Lambda Ж$ У миц с МВ в молодом возрасте. В связи с этим быи провеАен анализ морфометрических характеристик $\Lambda$ в группе миц старшего возраста, который показал развитие гипертрофии миокарда $\Lambda$ в группе МВ. Толщина $3 \mathrm{C}(12,6 \pm 1,4$ и $11,7 \pm 1,5$ мм соответственно, $\mathrm{p}=0,008)$ и МЖП $(11,5 \pm 1,2$ и $10,5 \pm 1,3$ мм соответственно, $\mathrm{p}=0,0008)$ оказались существенно больше у миц с признаками МВ.

Аалее были оценены величина и скорость систолической ЦА (рис. 2). Оказалось, что Аля миц с МВ характерно снижение величины ЦА большинства сегментов на среАинном и верхушечном уровнях $\Lambda Ж$ (рис. 3 ). ГАобальная ЦА в группе МВ оказалась недостоверно ниже по сравнению с контролем $(-8,8 \pm 5,2$ и $-21,52 \pm 6,1, \mathrm{p}=0,06)$. Скорость ЦА оказалась также существенно сниженной в 4 из 6 сегментов на срединном уровне и во всех 4 сегментах на верхушечном уровне. ГАобальная скорость ЦА среди киц с МВ составила $-1,3 \pm 0,4 \mathrm{c}^{-1}$, и была несколько ниже по сравнению с группой контромя $-1,5 \pm 0,5 \mathrm{c}^{-1}$, ра3личия недостоверны $(\mathrm{p}=0,06)$.

При оценке величины РА выявлено ее снижение в 5 из 6 сегментов на базальном уровне. В большинстве из них обнаружено также снижение скорости систолической PA (рис. 3). При этом отмечается некоторое повышение величины РА в 2 сегментах на верхушечном уровне, что, по-видимому, можно рассматривать как компенсаторный механизм.

\section{Обсужаение}

Таким образом, уточненные критерии МB, учитывающие специфичность отдельных костных признаков и генАерную принадлежность обследуемых миц, продемонстрировали свою перспективность в плане выявления структурных особенностей сердца и аорты, а также признаков систолической Аисфункции у бессимптомных пациентов.

Было показано, что у пациентов с признаками МВ уже в молодом возрасте удается выявить морфологические особенности сердечно-сосудистой системы, что в более стар- 
шем возрасте может приводить к значимым изменениям структуры и функции сердца. Так, у молодых мужчин с МВ выявляются относительно большие размеры начального и восходящего отАелов аорты. Это, оАнако, не позволяет говорить о расширении корня аорты в молодом возрасте, так как Z-критерий, учитывающий соотношение абсолютных размеров аорты к Аолженствующим значениям, не превышал пороговые значения. ОАнако в группе старшего возраста пограничное расширение корня аорты выявляется уже у четверти киц с МВ. При этом ни степень самого расширения, ни темпы его прогрессирования у таких пациентов, в отличие от больных с синаромом Марфана, не являются показанием Аля хирургической коррекции.

При оценке морфологических характеристик миокарда $\Lambda$ обнаружено, что у юношей с МВ отмечается тенденция к более высоким значениям массы миокарда, обусловленная большей толщиной миокарда МЖП и ЗС $\Lambda Ж$ по сравнению со сверстниками без признаков МВ. При этом указанные параметры не выходят за пределы нормальных значений. ОАнако среди пациентов с МВ старшего возраста выявленные тенденции приводят к значимому утолщению миокарда $\Lambda$ Ж. Большая толщина миокарда $\Lambda$ у миц с МВ уже в молодом возрасте сопровожАается более низкими значениями систолических ЦА и РА. Нами выявлены Аостоверно более низкие значения ЦА и ее скорости Амя большинства сегментов на срединном и верхушечном уровнях у пациентов с МВ по сравнению с контролем. Величина РА и ее скорость оказались значимо ниже в большинстве сегментов на базальном уровне.

Выявленные морфологические и функциональные изменения могут быть обусловлены нарушением нормальной трехмерной структуры соединительнотканного каркаса $\Lambda$ Ж. Аналогичные Аанные о более низких показателях систолической Аеформации на фоне концентрического ремоделирования, описанные Аля пациентов с синдромом Марфана и первичным ПМК $[18,21]$, обычно объясняют Аизрегумяцией сигнамьного пути TGF- $\beta$ (трансформирующего ростового фактора) [24]. По ранее опубликованным нами Аанным, у пациентов с МВ также отмечается активация TGF- $\beta$, что подтвержАается более высокими значения- ми концентрации этого цитокина в крови [25]. Это явцяется доказательством того, что $\mathrm{MB}$, равно как и синАром Марфана и первичный ПМК, следует относить к группе фибримиинопатий. Таким образом, у пациентов с МВ происходит реактивное ремодекирование $\Lambda$ в ответ на повышенную активацию TGF- $\beta$ сигнального пути. Кроме того, механизм поражения серАца при фибримлинопатиях может быть обусловлен гемодинамической нагрузкой на структурно неполноценную соеАинительную ткань.

ОАнако при синдроме Марфана имеет место снижение величины ЦА и РА практически всех сегментов $\Lambda Ж$, в то время как у Аиц с МВ происходит увеличение Аеформации некоторых сегментов, что носит, вероятно, компенсаторный характер, направленный на поддержание глобальной систолической функции $\Lambda Ж$. Можно преАполагать, что изменения систолической функции при МВ носят Аоброкачественный характер. В то же время нельзя не отметить, что возраст больных с синдромом Марфана, включенных в анализ [17], Аостоверно выше, чем в нашем исследовании ( $30 \pm 12$ и 20,1 $\pm 2,1$ мет соответственно, $\mathrm{p}=0,00001)$. Учитывая тот факт, что клинически значимые гипертрофия миокарда и расширение грудной аорты у миц с МВ могут быть обнаружены мишь на 5-6-м Аесятке жизни, исключить развитие декомпенсации в виле $\mathrm{CH}$ в более старшем возрасте на сегодняшний момент не представцяется возможным. Стоит напомнить, что и при Аругих фибримлинопатиях клинически значимые изменения, такие как расширение и расслоение аорты у больных синаромом Марфана, а также отрыв папимяярных мышц при классическом первичном ПМК, также развиваются отсрочено, в более старших возрастных группах $[2,4]$.

Исходя из вышесказанного, мица с МВ, по нашему мнению, Аолжны рассматриваться как группа повышенного риска развития кминически значимого расширения аорты и прогрессирования СН. Такие пациенты нужАаются в Аинамическом ЭхоКГ наблюдении с периодичностью в 5-10 мет [26]. Можно наАеяться, что Аальнейшие генетические исследования смогут помочь выделить факторы, приводящие к описанным изменениям миокарАа у миц с МВ.

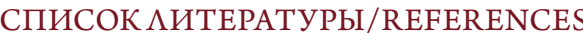

1. Земцовский Э. В., Анастасьева В. Г., Белан Ю. Б., Бржеский В. В., Викторова И.А., Верещагина Г.Н. и Ар. НаслеАственные нарушения соеАинительной ткани. Российские рекоменАации. Кардиоваскумярная терапия и профикактика. 2009;8 (6 S5): 2-24. [Zemtsovsky E. V., Anastasieva V.G., Belan Yu. B., Brjevsky V. V., Viktorova I. A., Verezhagina G. N. et al. Hereditary connective tissue disorders. Russian recommendations. Cardiovascular Therapy and Prevention. 2009;8 (6 S5):2-24.]

2. Наследственные нарушения соединительной ткани в кардиомогии. Аиагностика и мечение. Российские рекоменАации (I пересмотр). Российский кардиологический журнал. 2013; (1 S1):5-32. [Hereditary connective tissue disorders in cardiol- ogy. Diagnosis and treatment. Russian recommendations (first revision). Russian Journal of Cardiology. 2013; (1s1):5-32.] DOI:10.15829/1560-4071-2013-1s1-5-32

3. De Paepe A, Devereux RB, Dietz HC, Hennekam RCM, Pyeritz RE. Revised diagnostic criteria for the Marfan syndrome. American Journal of Medical Genetics. 1996;62 (4):417-26. DOI:10.1002/(SICI) 1096-8628 (19960424) 62:4<417::AIDAJMG15>3.0. CO;2-R

4. Loeys BL, Dietz HC, Braverman AC, Callewaert BL, De Backer J, Devereux RB et al. The revised Ghent nosology for the Marfan syndrome. Journal of Medical Genetics. 2010;47 (7):476-85. DOI:10.1136/jmg. 2009.072785 

5. Beighton P, De Paepe A, Steinmann B, Tsipouras P, Wenstrup RJ. Ehlers-Danlos syndromes: revised nosology, Villefranche, 1997. Ehlers-Danlos National Foundation (USA) and EhlersDanlos Support Group (UK). Am J Med Genet. 1998;77 (1):31-7. PMID:9557891

6. Malfait F, Francomano C, Byers P, Belmont J, Berglund B, Black J et al The 2017 international classification of the EhlersDanlos syndromes. American Journal of Medical Genetics Part C: Seminars in Medical Genetics. 2017;175 (1):8-26. DOI: 10.1002 / ajmg. c. 31552

7. Grahame R, Bird HA, Child A. The revised (Brighton 1998) criteria for the diagnosis of benign joint hypermobility syndrome (BJHS). J Rheumatol. 2000;27 (7):1777-9. PMID:10914867

8. Grahame R. Heritable disorders of connective tissue. Best Practice \& Research Clinical Rheumatology. 2000; 14 (2):34561. DOI: 10.1053 / berh. 1999.0069

9. Faivre L, Collod-Beroud G, Child A, Callewaert B, Loeys BL, Binquet $\mathrm{C}$ et al. Contribution of molecular analyses in diagnosing Marfan syndrome and type I fibrillinopathies: an international study of 1009 probands. Journal of Medical Genetics. 2008;45 (6):384-90. DOI:10.1136/jmg. 2007.056382

10. Земцовский Э. В., Мамев Э. Г., Реева С. В., Аунева Е. Б., Парфенова Н.Н., Аобанов М.Ю. и Ар. Аиагностика наслеАственных нарушений соеАинительной ткани. Итоги и перспективы. Российский карАиологический журнал. 2013; (4): 38-44. [Zemtsovsky E. V., Malev E. G., Reeva S. V., Luneva E. B., Parfenova N. N., Lobanov M. Y. et al. Diagnostics of inherited connective tissue disorders: achievements and future directions. Russian Journal of Cardiology. 2013; (4):38-43.]

11. Тимофеев Е. В., Зарипов Б. И., Цобанов М. Ю., Мамев Э. Г., Вютрих Е.В., Бергмане О.А. и Ар. Аолихостеномелия как критерий Аиагностики марфаноиАной внешности. Бюмметень феАерального центра серАца, крови и эндокриномогии им. В.А. Алмазова. 2013;21 (4):62-9. [Timofeev E. V., Zaripov B. I., Malev E. G., Lobanov M. Yu., Vyutrikh E. V., Bergmane O.A., Zemtsovsky E. V. Dolichostenomelia as an criterion of the marfanoid habitus. Bulletin of Almazov Federal Heart, Blood and Endocrinology Centre. 2013;21 (4):62-9.]

12. Реева С. В., Малев Э. Г., Панкова И. А., Тимофеев Е. В., Земцовский Э. В. Вегетативная Аисфункция у Аиц молодого возраста с пролапсом митрального клапана и марфаноидной внешностью. Российский карАиологический журнал. 2013; (1): 23-7. [Reeva S. V., Malev E. G., Pankova I. A., Timofeev E. V., Zemtsovsky E. V. Autonomous dysfunction in young patients with mitral valve prolapse and Marfanoid habitus. Russian Journal of Cardiology. 2013;1 (99):23-27.]

13. Земцовский Э. В., Тимофеев Е. В., Мамев Э. Г.НаслеАственные нарушения (Аиспиазии) соеАинительной ткани. Какая из Авух Аействующих национальных рекоменАаций преАпочтительна? ПеАиатр. 2017;8(4):6-18. [Zemtsovsky EV, Timofeev EV, Malev EG. Inherited disorders (dysplasia) of the connective tissue. Which of the two existingnational recommendations is preferable? Pediatrician (St Petersburg). 2017;8 (4):6-18] DOI:10.17816/PED846-18

14. Yetman AT, Bornemeier RA, McCrindle BW. Long-term outcome in patients with Marfan syndrome: is aortic dissection the only cause of sudden death? J Am Coll Cardiol. 2003;41 (2):329-32. PMID: 12535830

15. De Backer JF, Devos D, Segers P, Matthys D, François K, Gillebert TC et al. Primary impairment of left ventricular function in Marfan syndrome. International Journal of Cardiology. 2006; 112 (3):353-8. DOI:10.1016/j. ijcard. 2005.10.010

16. Rybczynski M, Koschyk DH, Aydin MA, Robinson PN, Brinken T, Franzen $\mathrm{O}$ et al. Tissue Doppler imaging identifies myocardial dysfunction in adults with marfan syndrome. Clinical Cardiology. 2007;30 (1):19-24. DOI:10.1002/ clc. 3

17. Kiotsekoglou A, Sutherland GR, Moggridge JC, Nassiri DK, Camm AJ, Child AH. The unravelling of primary myocardial impairment in Marfan syndrome by modern echocardiography. Heart. 2009;95 (19):1561-6. DOI: 10.1136/hrt. 2008.152934

18. Малев Э.Г., Реева С.В., Тимофеев Е.В., Пшепий А.Р., Коршунова А. А., Панкова И.А. и Ар. Систолическая и Аиастолическая функция $\Lambda Ж$ при пролапсе митрального клапана. Журнал Сердечная Недостаточность. 2012;13 (1):26-31. [Malev E. G., Reeva S. V., Timofeev E.V., Pshepiy A. R., Korshunova A. L., Pankova I. A., Zemtsovskiy E. V. Systolic and diastolic function of the left ventricle at mitral valve prolapse. Russian heart Failure Journal. 2012;13 (1):26-31]

19. Meijboom LJ, Timmermans J, van Tintelen JP, Nollen GJ, De Backer J, van den Berg MP et al. Evaluation of left ventricular dimensions and function in Marfan's syndrome without significant valvular regurgitation. The American Journal of Cardiology. 2005;95 (6):795-7. DOI:10.1016/j. amjcard. 2004.11.042

20. Алехин М. Н. КАиническое использование показателей продольной систолической Аеформации мевого желудочка серАца. Кремлевская меАицина КАинический вестник. 2017; 1(4):101-11. [Alekhin M. N. Klinicheskoe ispol'zovanie pokazatelej prodol'noj sistolicheskoj deformacii levogo zheludochka serdca. Kremlevskaya medicina Klinicheskij vestnik. 2017;1(4):101-11]

21. Kiotsekoglou A, Saha S, Moggridge JC, Kapetanakis V, Govindan M, Alpendurada F et al. Impaired Biventricular Deformation in Marfan Syndrome: A Strain and Strain Rate Study in Adult Unoperated Patients: Impaired Myocardial Function in Marfan Syndrome. Echocardiography. 2011;28 (4):416-30. DOI: $10.1111 / j .1540-8175.2010 .01359 . x$

22. Земцовский Э. В., Парфенова Н. Н., Реева С. В., Малев Э. Г.,

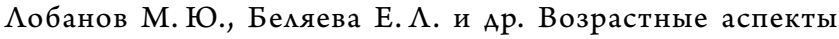
проблемы диагностики наслеАственных нарушений структуры и функции соединительной ткани. Артериальная гипертензия. 2008;14 (2 S2):63-8. [Zemtsovsky E. V., Parfenova N. N., Reeva S. V., Malev E. G., Lobanov M. Yu., Belyaeva E. L. et al. Age aspects of the problem of diagnosis of hereditary disorders of connective tissue structure and function. Arterial Hypertension. 2008;14 (2 S2):63-8]

23. Mor-Avi V, Lang RM, Badano LP, Belohlavek M, Cardim NM, Derumeaux G, и ар. Current and Evolving Echocardiographic Techniques for the Quantitative Evaluation of Cardiac Mechanics: ASE/EAE Consensus Statement on Methodology and Indications Endorsed by the Japanese Society of Echocardiography. European Journal of Echocardiography. 2011;12(3):167-205. DOI:10.1093/ejechocard/jer021

24. CookJR, Carta L, Galatioto J, Ramirez F. Cardiovascular manifestations in Marfan syndrome and related diseases; multiple genes causing similar phenotypes. Clinical Genetics. 2015;87(1):11-20. DOI:10.1111/cge.12436

25. Luneva E, Malev E, Alex, Korshunova R, Reeva S, Timofeev E et al. Cardiomyopathy in patients with Marfan syndrome and marfanoid habitus. Current Research: Cardiology. 2017;4(1):138-42. DOI:10.4172/2368-0512.1000082

26. Hiratzka LF, Bakris GL, Beckman JA, Bersin RM, Carr VF, Casey DE, и Ap. 2010 ACCF/AHA/AATS/ACR/ASA/SCA/ SCAI/SIR/STS/SVM Guidelines for the Diagnosis and Management of Patients With Thoracic Aortic Disease: A Report of the American College of Cardiology Foundation/American Heart Association Task Force on Practice Guidelines, American Association for Thoracic Surgery, American College of Radiology, American Stroke Association, Society of Cardiovascular Anesthesiologists, Society for Cardiovascular Angiography and Interventions, Society of Interventional Radiology, Society of Thoracic Surgeons, and Society for Vascular Medicine. Circulation. 201 0;121(13):e266-369. DOI:10.1161/ CIR.0b013e3181d4739e

Материал поступим в реАакцию 22/11/2017 